\title{
PRELIMINARY RESULTS REGARDING THE FRUIT QUALITY AND YIELD OF SOME BLUEBERRY GENOTYPES
}

\author{
Oana Hera ${ }^{1,2 *}$, Monica Sturzeanu ${ }^{1}$, Răzvan Teodorescu ${ }^{2}$ \\ ${ }^{1}$ Research Institute for Fruit Growing Pitesti, 402 Mărului Street, Pitești, Argeș, RO 117450, Romania \\ ${ }^{2}$ University of Agronomic Sciences and Veterinary Medicine of Bucharest, 59 Mărăști Blvd., \\ District 1, Bucharest, Romania
}

\begin{abstract}
Vaccinium corymbosum is one of the berry species with economic and food interest to Romanian growers and consumers. The development of blueberrty crop is a result of breeding activity, which has generated many cultivars of quality fruit and high productivity. The characters that are of economic interest in the cultivation of blueberries depend on the area of cultivation where the new cultivars are obtained. The study was conducted in summer 2020 in an experimental plot established in 2015 with seven blueberry genotypes, at Research Institute for Fruit Growing, Pitesti, Romania in the Small Fruit Laboratory, having an experience in the field of more than 40 years. The objective at this study is to compare some of fruit characteristics from genotypes 'Azur', 'Delicia', 'Duke', 'Northblue', 'Simultan', '4/6' and '6/38': plant yield, average fruit weight, fruit length, fruit diameter, the soluble solids, fruit acidity or pH, fruit firmness. During this study 'Delicia' cv. proved to have the highest production per plant (4.20 $\mathrm{kg}$ plant), the highest values of fruit diameter $(19.70 \mathrm{~mm})$, and the highest value of fruit total titratable acidity $(01.25 \%)$.
\end{abstract}

Key words: Vaccinium corymbosum fruit characteristics, breeding

\section{Introduction}

The blueberry (Vaccinium corymbosum) belongs to the Ericaceae family and the genus Vaccinium section Cyanococcus. Blueberry is one of the berry species with economic and food interest for growers and consumers. After Hancock et al., 2008, the primary focus of blueberry breeding programs in the United States is to improve two types of highbush blueberry cultivars (Vaccinium corymbosum, $2 n=4 x=48$ ) termed northern highbush blueberry (NHB) and southern highbush blueberry (SHB), the rabbiteye $(\mathrm{RY})$ cultivars (Vaccinium virgatum, $2 n=6 x=$ 72) and their interspecific hybrids.

First blueberry plantation in Romania was established in 1968 at the Bilcești, Research Station situated in a mountain region (Asănică A. et al., 2016). The blueberry plant require specific soils with a low $\mathrm{pH}$ value (Williamson et al., 2006), high humus content, with stabilised groundwater level (Starast et al., 2002). The bushes at the natural sites grow in the forest soils with a low nutrient level.

Due to high yields and special nutritional qualities (high content of vitamins and minerals), in recent years, blueberry production and consumption have increased (Mengist et al., 2020; RodriguezSaona et al., 2019). Furthermore, blueberry production has gained consumer`s and commercial 
interest based as recent studies regarding blueberry and their multiple health benefits improving lowering pressure blood, protecting against heart attack, cancer preventing, mental health and managing diabetes (Martineau et al., 2006; Krikorian et al., 2010; Norberto et al., 2013; Sun et al., 2019). About $10 \%$ of the worldwide highbush blueberry cultivation is located in Europe according to Faostat.ro. The blueberry breeding program was established at the Research Institute for Growing in 1982. Improving yield, fruit quality and adaptation to the Romania climate were the initial targets. Selection for new material began using F1 seedlings and open pollinated crosses obtained from the USA. After 1990, some of the early releases included the nine northern highbush cultivars: 'Safir', 'Azur', 'Lax', 'Pastel', 'Prod', 'Augusta', 'Simultan', 'Delicia' and 'Vital' (Mladin P. et al., 2007). The development of blueberry crop is a result of breeding activity, generating many cultivars with good quality fruit and high productivity. The characters that are of economic interest in the cultivation of blueberries depend on the area of cultivation when the new variety is obtained. The cultivars selection for use as genitors is one of the most important decisions for berry breeders and the development of new blueberry cultivars. The objective of this study is to evaluate attributes of fruit quality and production of some blueberry genotypes to be recommended as potential parents in future breeding programs.

\section{MATERIAL AND METHODS}

The study was conducted in summer 2020 in an experimental plot established in 2015 with seven blueberry genotypes, in the Small Fruit Laboratory, at the Research Institute for Fruit Growing, Pitesti, Romania. The experiment was monofactorial, where Factor A (genotype) had seven graduations: $a 1=$ 'Azur', a2= 'Delicia', a3= 'Duke', a4= 'Northblue', a5= 'Simultan', a6= '4/6' and a7= ' $6 / 38$ '.

The experiment was organized according to the method of plots subdivided into 3 repetitions on each genotype, with 4 plants per repetition. The planting distance was $3 \mathrm{~m}$ between rows $\mathrm{x} 1 \mathrm{~m}$ along the rows. The prevailing soil type in the trials field was medium-textured and heavy-clay soils: clay-illuvial that had medium to low humus content.

During the study period, the annual average temperature was $11.8^{\circ} \mathrm{C}$, being with $1.8^{\circ} \mathrm{C}$ higher than the multiannual average temperature of the area of 51 years (respectively, $10.0^{\circ} \mathrm{C}$ ).

The average annual rainfall was $679.1 \mathrm{~mm}$, being very close to the multiannual average of rainfall from the area $(680 \mathrm{~mm})$.

The relative humidity of the air had an average value lower than the multiannual average $(67.9 \%$ in 2020 compared to $75.5 \%$ average value of the last 51 years).

At harvest, the yield per plant was weighed and summing the weights to give a cumulative production. For average fruit weight was determined by weighing 50 berries with the aid HL-400 digital balance. The firmness of blueberry was determined for 50 fruits with the nondestructive testing penetrometer Bareiss HPE II, with a measuring surface at $25 \mathrm{~cm}^{2}$. The diameter and length of the blueberry fruit were determined by measurements 50 fruits per sample by a digital caliper. Testing juice of 50 fruits was analyzed for soluble solid content by Hanna Instruments 96801 and for $\mathrm{pH}$ using a pH-meter (ISFET $\mathrm{pH}$ Meter, IQ 125, Japan).

The experimental data were classified using the MS Excel facilities, SPSS 14.0 software and the test for determining the significance of differences between the variants was multiple range test DUNCAN, for error probability of $\leq 0.05$ their statistical processing was carried out using the Duncan test. 


\section{RESULTS AND DISCUSSIONS}

The seven genotypes studied recorded variation in production. The accumulated yield per plant for the seven genotypes studied was statistically different. The highest production was obtained by 'Delicia' cv. (4.20 kg plant) (Figure 1). The genotypes 'Simultan', 'Azur' and '6/38' recorded the lowest values $(1.91 \mathrm{~kg}, 1.48 \mathrm{~kg}$ and $1.67 \mathrm{~kg}$ ). In New Zealand, Scalzo et al. (2013) evaluated the yield of 'Blue Bayou', 'Sunset Blue', 'Blue Moon', 'Dolce Blue', 'Sky Blue', 'Central Blue' and 'Velluto Blue' and on average, in fifth years, the yield was 3,355 kg/plant. The comparison between the cultivars studied showed that there were significant differences in fruit size and weight. Average fruit weight recorded similar values (Figure 1). The genotype '6/38' had a highest value $(2.57 \mathrm{~g})$, and the others follow very closely: '4/6' (2.53 g), 'Delicia' (2.37 g), 'Azur' (2.32 g), 'Northblue' (2.13 g), 'Duke' (1.93 g), 'Simultan' (1.83 g). These results are similar with those obtained by Ancu et al (2019), who evaluated the fruit weight at 32 genotypes and showed values between $1.62 \mathrm{~g}$ and 3.92 $\mathrm{g}$ and 'Delicia' cv. recorded same value as our study, respectively $2.76 \mathrm{~g}$.

The fruit size had a wide variability being influenced by the genotypes, cultivation conditions and technology of pruning. In the last summer, the genotype 'Azur' recorded the highest value of the fruit length $(14.36 \mathrm{~mm})$, followed by 'Delicia' (14.33 mm), 'Northblue' (12.79 mm), '6/38' (12.44 mm), 'Simultan' (11.99 mm), 'Duke' (11.45 mm) (Figure 2). Regarding fruit diameter of all studied genotypes those varied significantly. The highest values of fruit diameter were registered by the genotypes 'Delicia' (19.70 mm), 'Azur' (19.02 mm), 'Northblue' (16.34 mm), '4/6' (16.05 mm), 'Duke' (15.51 mm), '6/38' (15.34 mm). The genotype 'Simultan' obtained the lowest value (14.42 $\mathrm{mm}$ ) (Figure 2).

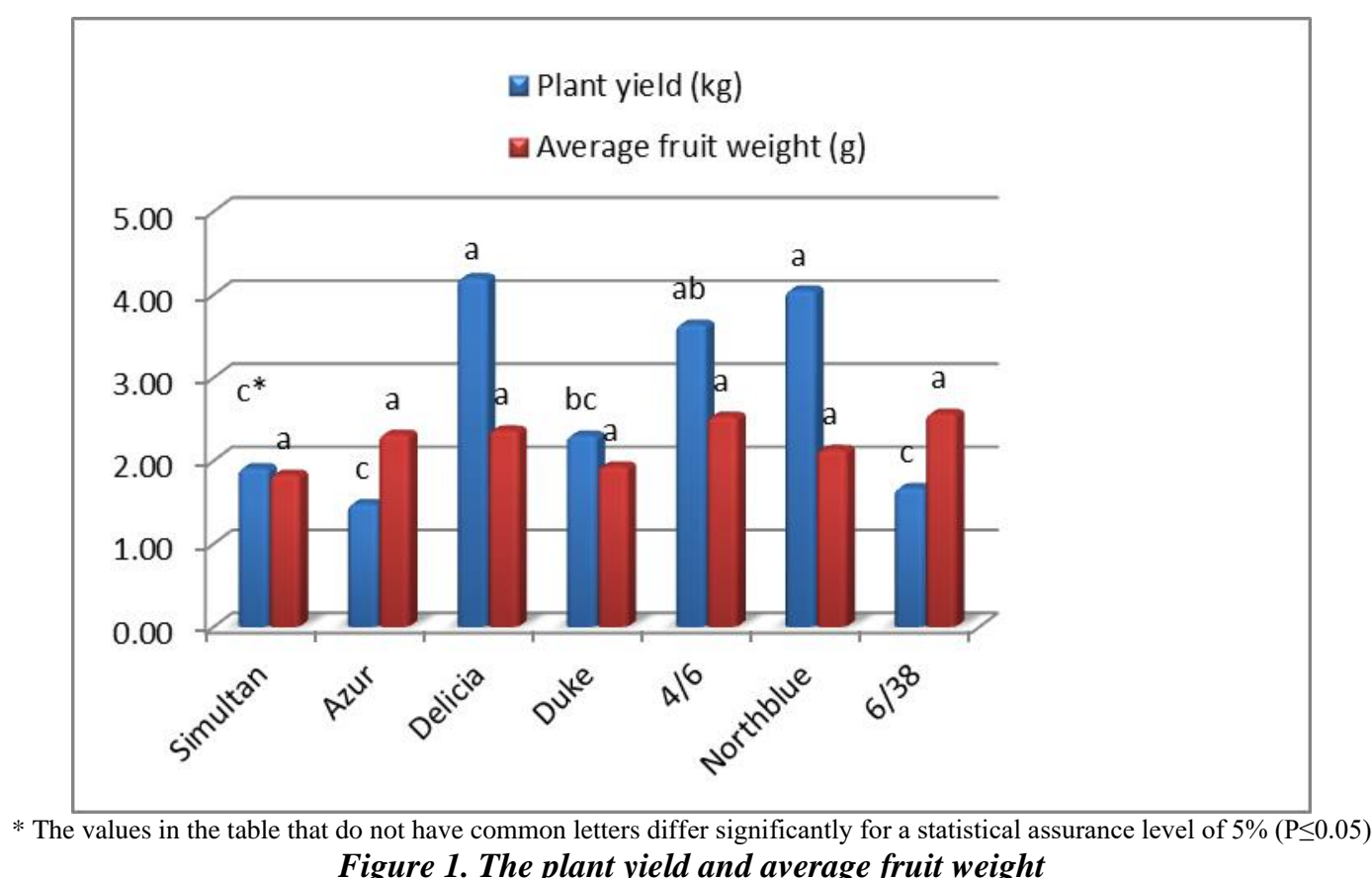

In our study, a significant influence on the soluble solids content was recorded for genotype 'Duke' with the highest value of this parameter $\left(12.44^{\circ}\right.$ Brix $)$ and the genotype '4/6' recorded the lowest value $\left(8.55^{\circ}\right.$ Brix) (Figure 3). In Colombia, Guasca, Cortés-Rojas et al. (2014) studied to compare 


\section{Current Trends in Natural Sciences}

Vol. 10, Issue 20, pp. 79-84, 2021

https://doi.org/10.47068/ctns.2021.v10i20.011

Current Trends in Natural Sciences (on-line)

the crop yield and some quality related aspects of the blueberry cultivars 'Biloxi' and 'Sharpblue' in a commercial crop. On average, the TSS content of the harvested fruits was in a range of 12.4 to $14.5^{\circ}$ Brix for both cultivars.

Regarding the fruit firmness, significant differences were found between genotypes and ranged: from $19.73 \mathrm{~N}$ ('6/38') to $36.03 \mathrm{~N}$ ('4/6') (Figure 3).

The total titratable acidity expressed as citric acid showed statistical differences between the genotypes 'Delicia' with the highest value $(01.25 \%)$ and 'Simultan' with the lowest value $(0.12 \%)$ Figure 4. The fruit $\mathrm{pH}$ of the studied genotypes ranged from 3.27 for the '6/38' genotype to 3.92 for 'Azur' genotypes (Figure 4).

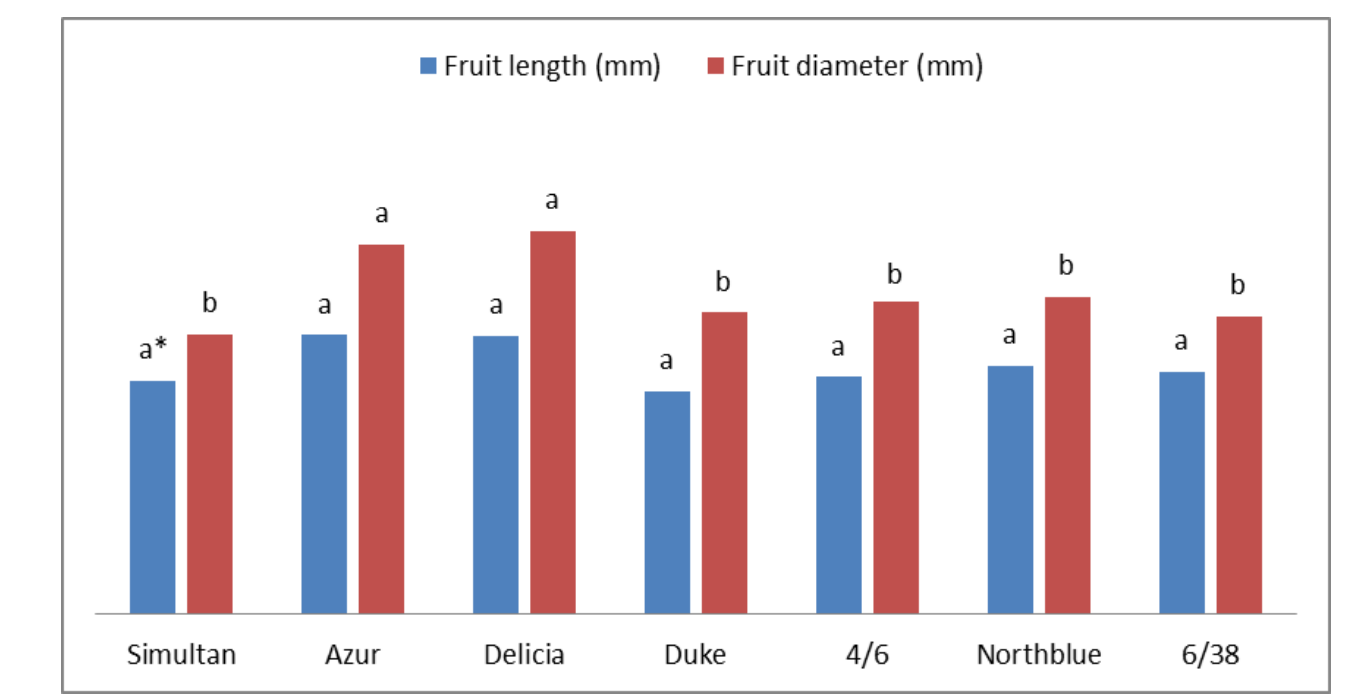

* The values in the table that do not have common letters differ significantly for a statistical assurance level of $5 \%(\mathrm{P} \leq 0.05)$

Figure 2. The fruit length and diameter

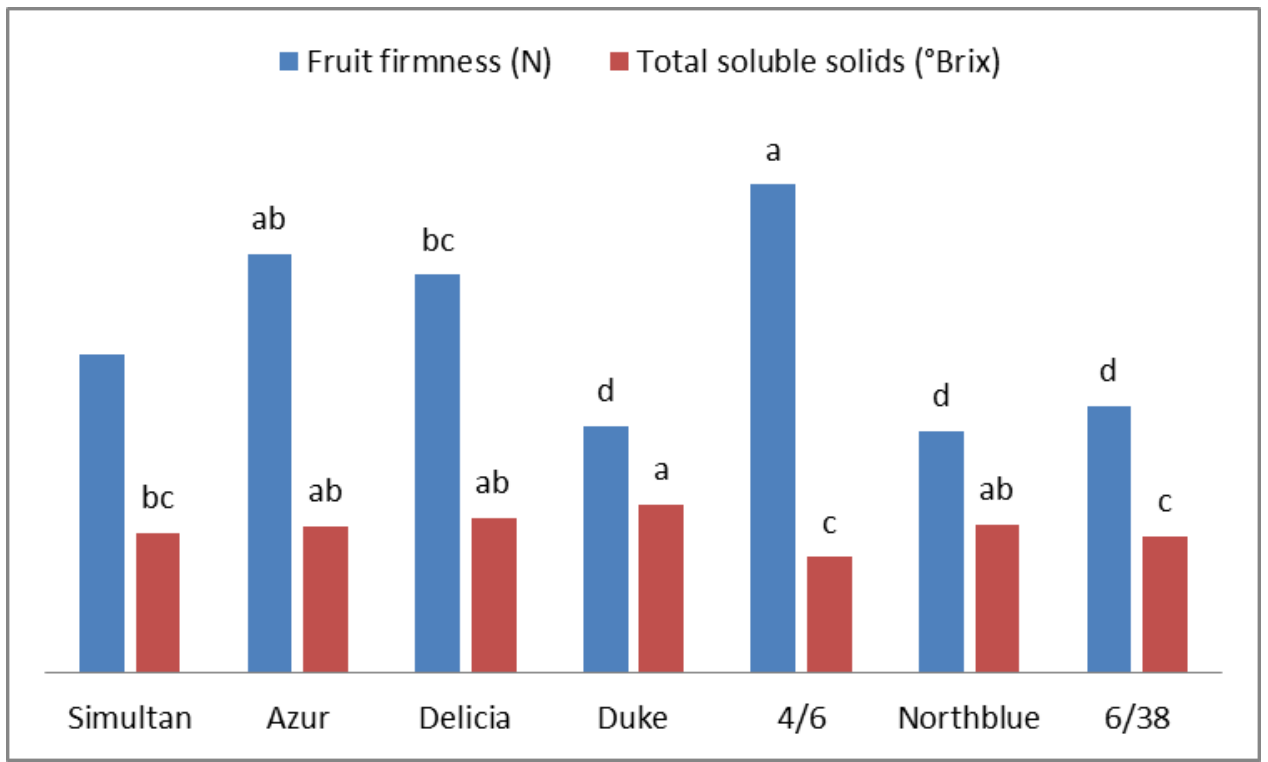

* The values in the table that do not have common letters differ significantly for a statistical assurance level of 5\% (P $\leq 0.05$ ) Figure 3. The fruit firmness and total soluble solids 


\section{Current Trends in Natural Sciences}

Vol. 10, Issue 20, pp. 79-84, 2021

https://doi.org/10.47068/ctns.2021.v10i20.011

Current Trends in Natural Sciences (on-line)

ISSN: 2284-953X

Current Trends in Natural Sciences (CD-Rom)

ISSN-L: 2284-9521

ISSN: 2284-9521

ISSN-L: 2284-9521

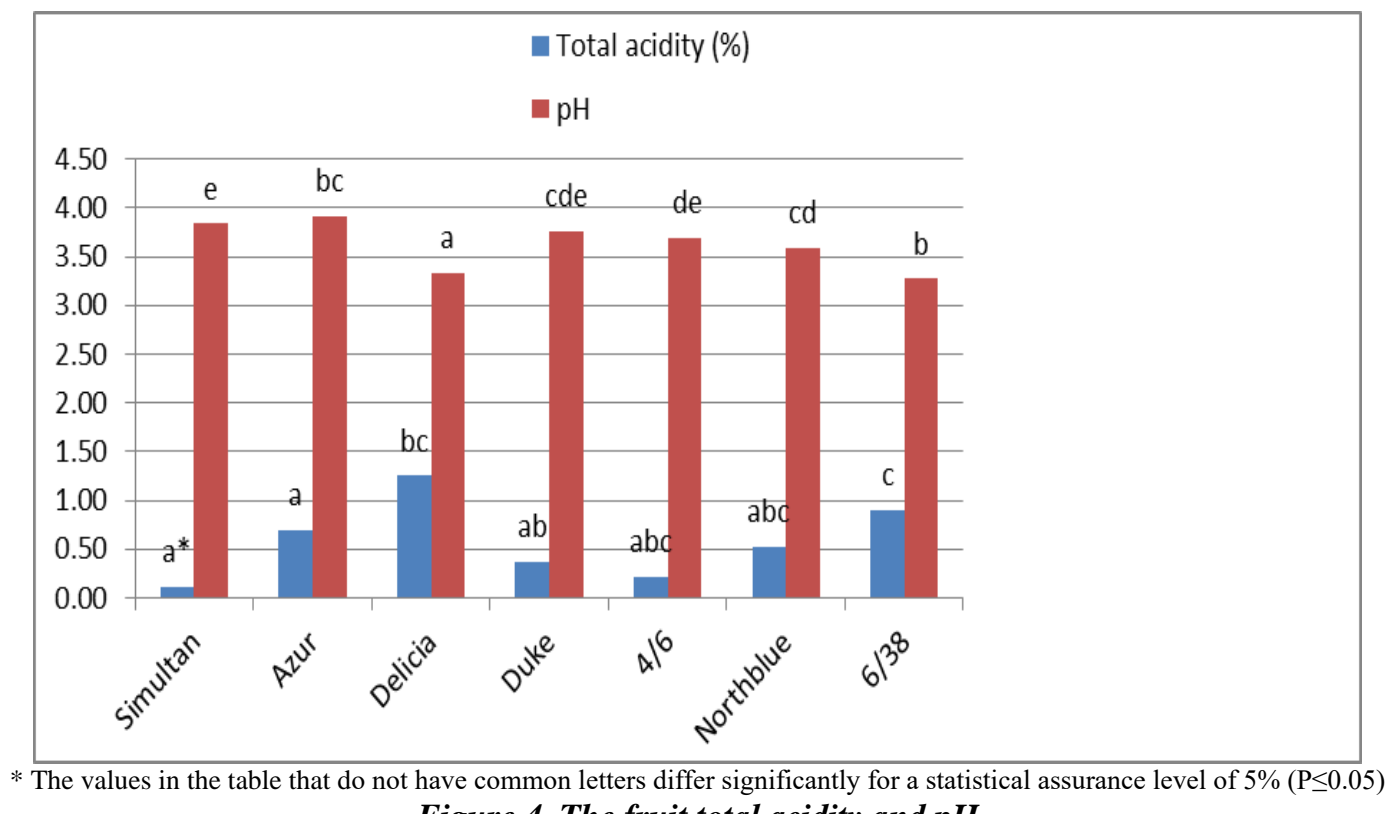

Figure 4. The fruit total acidity and $\mathrm{pH}$

\section{CONCLUSIONS}

Among the seven studied genotypes, 'Delicia' cv. recorded the highest production per plant, the highest values of fruit diameter and the highest value of fruit total titratable acidity.

Based on this evaluation and the following years of the seven genotypes studied, can be recommended as potential parents in future breeding programs as well as for their extension in commercial cultures.

\section{REFERENCES}

Ancu, I., Sturzeanu, M., Song, Y.U., Kwon, M.K., Suh, D.W. (2019). Evaluation of highbush blueberry clonal progenies for fruit quality. Acta Hortic. 1242. ISHS 2019. DOI 10.17660/ActaHortic.2019.1241.39.

Asănică, A., Delian, E., Tudor, V., Teodorescu, R.I. (2017). Physiological activity of some blueberry varieties in protected and outside conditions. AgroLife Scientific Journal, Volume 6, Number 1, 31-39.

Krikorian, R., Shidler, M. D., Nash, T. A., Kalt, W., Vinqvist-Tymchuk, M. R., Shukitt-Hale, B., et al. (2010). Blueberry supplementation improves memory in older adults. J. Agric. Food Chem. 58, 3996-4000. DOI: $10.1021 /$ jf9029332.

Martineau, L.C., Couture, A., Spoor, D., Benhaddou-Andaloussi, A., Harris, C.,Meddah, B., et al. (2006). Anti-diabetic properties of the Canadian Lowbush blueberry Vaccinium angustifolium Ait. Phytomedicine 13, 612-623. DOI: 10.1016/j.phymed.2006.08.005.

Mengist, M. F., Grace1, M.H., Xiong, J., Kay, C. D., Bassil, N., Hummer, K., Ferruzzi, M. G., Lila, M. A. Iorizzo, M. (2020). Diversity in Metabolites and Fruit Quality Traits in Blueberry Enables Ploidy and Species Differentiation and Establishes a Strategy for Future Genetic Studies. Front. Plant Sci., https://doi.org/10.3389/fpls.2020.00370.

Mladin, P., Mladin, Gh., Ancu, I. (2007). Results of the breeding blueberry. Fruit Growing Research, vol. XXIII: 26-31.

Norberto, S., Silva, S., Meireles, M., Faria, A., Pintado, M., and Calhau, C. (2013). Blueberry anthocyanins in health promotion: a metabolic overview. J. Funct. Foods 5, 1518-1528. doi: 10.1016/j.jff.2013.08.015.

Rodriguez-Saona, C., Vincent, C., and Isaacs, R. (2019). Blueberry IPM: past successes and future challenges. Ann. Rev. Entomol. 64, 95-114. doi: 10.1146/annurev-ento-011118-112147.

Sun, Y., Nemec-Bakk, A.S., Mallik, A.U., Bagchi, A.K., Singal, P.K., and Khaper, N. (2019). Blueberry extract attenuates doxorubicin-induced damage in H9c2 cardiac cells. Can. J. Physiol. Pharmacol. 97, 880-884. doi: 10.1139/cjpp-2019-0031 


\section{Current Trends in Natural Sciences}

Vol. 10, Issue 20, pp. 79-84, 2021

https://doi.org/10.47068/ctns.2021.v10i20.011

Current Trends in Natural Sciences (on-line)

ISSN: 2284-953X

Current Trends in Natural Sciences (CD-Rom)

ISSN-L: 2284-952

ISSN: 2284-9521

Scalzo, J., Stevenson, D. and Hedderley, D. (2013). Blueberry estimated harvest from seven new cultivars: fruit and anthocyanins. Food Chem. 139, 44-50. Doi: 10.1016/j.foodchem.2013.01.091

Starast, M., Karp, K., Paal, T. (2002). The effect of using different mulches and growth substrates on half-highbush blueberry (Vaccinium corymbosum x V. angustifolium) cultivars' Northblue' and' Northcountry'. Acta Hortic. 574, 281-286.

Williamson, J., Krewer, G., Pavlis, G., Mainland, C. (2006). Blueberry Soil Management, Nutrition and Irrigation. Blueberries for Growers, Gardeners and Promoters. EO, Gainesville, FL.

Hancock, J.F., Lyrene, P., Finn, C.E., Vorsa, N. \& Lobos, G.A. (2008). Blueberries and cranberries, p. 115-150. In: J.F. Hancock (ed.). Temperate fruit crop breeding: Germplasm to genomics. Springer, New York, NY 